\title{
ETHNIC ATTRITION, ASSIMILATION, AND THE MEASURED HEALTH OUTCOMES OF MEXICAN AMERICANS
}

\author{
Francisca M. Antman, Brian Duncan, and Stephen J. Trejo*
}

February 24, 2020

The literature on immigrant assimilation and intergenerational progress has sometimes reached surprising conclusions, such as the puzzle of immigrant advantage which finds that Hispanic immigrants sometimes have better health than U.S.-born Hispanics. While numerous studies have attempted to explain these patterns, almost all studies rely on subjective measures of ethnic selfidentification to identify immigrants' descendants. This can lead to bias due to "ethnic attrition," which occurs whenever a U.S.-born descendant of a Hispanic immigrant fails to self-identify as Hispanic. In this paper, we exploit information on parents' and grandparents' place of birth to show that Mexican ethnic attrition, operating through intermarriage, is sizable and positively selected on health, making subsequent generations of Mexican immigrants appear less healthy than they actually are. Consequently, conventional estimates of health disparities between Mexican Americans and non-Hispanic whites as well as those between Mexican Americans and recent Mexican immigrants have been significantly overstated.

JEL Classification: J15, J12, I14

Keywords: assimilation, immigrant health advantage, ethnic attrition, Hispanic health paradox

*We thank Brian Cadena, Terra McKinnish, Joseph P. Price, Fernando Riosmena, and conference participants at the Society of Labor Economists meeting and the Western Economics Association International meeting for their feedback. This work also benefited from the comments of four anonymous referees and the Editor, Klaus F. Zimmermann.

Antman (corresponding author): University of Colorado Boulder, Department of Economics, 256 UCB, Boulder, CO 80309, Phone (303) 492-8872, Fax (303) 492-8960, francisca.antman@colorado.edu

Duncan: University of Colorado Denver, Department of Economics, Campus Box 181, Denver, CO 80217-3364, Phone (303) 315-2041, Fax (303) 315-2048, brian.duncan@ucdenver.edu

Trejo: University of Texas at Austin, Department of Economics, 2225 Speedway Stop C3100, Austin, TX, 78712-1690, Phone (512) 475-8512, Fax (512) 471-3510, trejo@ austin.utexas.edu 


\section{INTRODUCTION}

There is now a vast literature documenting the health of immigrants and their U.S.-born descendants. One strand of this literature centers on long-term integration and forms a key element in the heated debate over immigration policy, documenting disparities between U.S.-born Hispanics and non-Hispanic whites on measures of health (Hummer et al. 2007; Antecol and Bedard 2006), as well as other measures of human capital (Borjas 1994; Smith 2003). A second strand of the immigrant health literature centers on the existence of an immigrant health advantage, exploring whether $1^{\text {st }}$ generation Hispanic immigrants are in better health than U.S.-born Hispanics (Singh and Siahpush 2002; Bates et al. 2008; Acevedo-Garcia et al., 2005; Tavernise 2013). ${ }^{1}$ These studies are closely related to the broader literature on the Hispanic Health Paradox, which attempts to explain why Hispanics appear to be in better health than non-Hispanic whites on some, though not all, measures of health, despite having lower socioeconomic status (Riosmena et al. 2015).

While the literature has explored the roles of selective migration (Palloni and Arias 2004; Riosmena et al. 2012) and regression toward the mean (Giuntella 2017) in explaining the Hispanic Health Paradox more broadly, ${ }^{2}$ the predominant explanation is the negative acculturation hypothesis (Escarce et al. 2006; National Research Council 2006). According to this view, immigrants arrive in the U.S. with habits and customs that are more protective of health and gradually assimilate to less-healthy U.S. norms (Antecol and Bedard 2006; Riosmena et al. 2014).

\footnotetext{
${ }^{1}$ Additional work in this literature examines whether any health advantage erodes over time within the 1st immigrant generation (e.g. Acevedo, et al. 2010). Since our study makes comparisons across immigrant generations, however, we do not focus on years since migration.

${ }^{2}$ With regard to death rates in particular, one explanation sometimes offered for the paradox vis-à-vis non-Hispanic whites stems from differences in reporting of ethnic identity by next-of-kin on death certificates relative to selfreporting of ethnicity on national surveys (Rosenberg 1999). While investigations of this explanation do not constitute an extensive portion of the literature, they do hint at problems inherent in the use of subjective measures of ethnic identity more broadly.
} 
Ironically, this means that just as the process of intergenerational assimilation may lead to convergence in health status between U.S.-born Hispanics and non-Hispanic whites, assimilation may also erode any health advantage held by $1^{\text {st }}$ generation immigrants.

Importantly, the literature exploring these questions relies almost universally on selfreported ethnic identity to identify Hispanic individuals. In contrast, several recent studies have emphasized the importance of distinguishing between self-identification and ancestry in making comparisons across generations and ethnic groups (Alba and Islam 2009; Duncan and Trejo 2011a, 2011b, 2016, 2017; Antman and Duncan 2015). Most significantly, Duncan and Trejo (2011a) document significant rates of Mexican "ethnic attrition" which occurs whenever a U.S.-born descendant of a Mexican immigrant fails to self-identify as Mexican. Moreover, this pattern of ethnic attrition is found to be selective on socioeconomic status (SES): the descendants of Mexican immigrants who do not identify as Mexican are more educated than those who self-identify, resulting in a downward bias in estimates of intergenerational educational progress for Mexican Americans.

This paper explores whether ethnic attrition is also selective on health and how that selection process may bias perceptions of long-term integration vis-à-vis non-Hispanic whites and estimates of any $1^{\text {st }}$ generation health advantage compared with U.S.-born Hispanics. To focus the analysis, we restrict attention to the experience of Mexicans in particular, as they overwhelmingly form the largest Hispanic origin group in the United States (Motel and Patten 2012). Thus, we explore the extent to which focusing only on groups of self-identified Mexicans gives an incomplete picture of intergenerational health profiles of all Mexican Americans by obscuring the experience of individuals with Mexican ancestry who do not identify as Mexican. Importantly, this problem plagues virtually all health studies of the descendants of immigrants since they rely 
on subjective measures of ethnic self-identification rather than on more objective measures of lineage. Instead, we use parents' and grandparents' place of birth to more objectively identify descendants of Mexican immigrants. Thus, we investigate how any selection into ethnic attrition might bias estimates of the health of U.S-born Mexicans when the analysis sample consists solely of those who self-identify as Mexican. To explore possible mechanisms, we investigate whether intermarriage is also selective on health and whether intermarriage is linked to the ethnic attrition that we observe.

On the one hand, one might expect a positive correlation between health, intermarriage, and ethnic attrition, since the latter two factors are positively correlated with SES just as health and SES are positively correlated (Adler and Ostrove 2006). Since ethnic attritors approach the SES of non-Hispanic whites more rapidly than those who continue identifying as Mexican, one might also expect health outcomes of ethnic attritors to converge more quickly with those of nonHispanic whites, at least relative to the path of self-identified Mexicans. Thus, one would expect that focusing only on self-identified Mexicans would make it appear that Mexicans are in worse health than they actually are. This would result in overestimated gaps between U.S.-born Mexicans and non-Hispanic whites, making Mexicans look more poorly assimilated. Assuming a $1^{\text {st }}$ generation health advantage exists, this would also lead to an overestimated gap between Mexicans immigrants and U.S.-born Mexicans.

On the other hand, Mexican self-identification itself might arguably serve as a measure of acculturation, since individuals with Mexican ancestry who do not identify as Mexican might be more readily identifying with the mainstream non-Hispanic white culture instead. Assuming a $1^{\text {st }}$ generation health advantage exists at the outset, one might then expect ethnic attritors to make lifestyle choices closer to the mainstream and thus adopt less-healthy lifestyles than individuals 
who identify as Mexican. ${ }^{3}$ This type of mechanism would be consistent with the negative acculturation hypothesis. If these less-healthy behaviors are more common among ethnic attritors than non-attritors, we should expect that calculations that exclude individuals based on their lack of Mexican self-identification would make Mexicans appear to be in better health. As a result, we should expect to underestimate the gap between U.S.-born Mexicans and non-Hispanic whites. The same would be true for the gap between Mexicans immigrants and U.S.-born Mexicans, again assuming the health outcome under study implied a $1^{\text {st }}$ generation advantage.

Since negative acculturation and positive socioeconomic factors are both possible channels contributing to the over- or under-estimates of health premiums assessed over generations and across ethnic groups, we investigate these questions empirically. We find that at higher-order immigrant generations, ethnic attritors display better health outcomes than non-attritors and are closer to those of non-Hispanic whites. We also show that this pattern can be traced to selective intermarriage: marriages between Mexicans and non-Mexicans are more likely to involve spouses in better health, and are more likely to produce children that are not identified as Mexican who are also in better health. Moreover, once we control for parental health and SES, the health differential by ethnic attrition disappears, reinforcing the view that the relationship between ethnic attrition and child health is driven by parental characteristics. Together, this collection of results implies that estimates relying on ethnic self-identification bias researchers toward finding that U.S.-born Mexican Americans are in worse health than they actually are. Consequently, conventional estimates of health disparities between Mexican Americans and non-Hispanic whites as well as

\footnotetext{
${ }^{3}$ This is similar to the mechanism suggested by Giuntella (2016) to be the root cause for the decline in birth weight observed across immigrant generations, which he attributes to the intermarriage of non-Hispanic whites with $2^{\text {nd }}$ generation Hispanic immigrants who are then more likely to adopt risky behaviors such as smoking during pregnancy.
} 
those between Mexican Americans and recent Mexican immigrants have been significantly overstated.

One important caveat to be noted is that the only measure of health available in our data set, the Current Population Survey (CPS), is self-rated health (SRH) status. This may raise concerns about whether SRH is a good measure for documenting health disparities, which we address directly in Section II.A. In particular, we compare SRH with a wide array of measures used in the health literature, but not available in the CPS, to show that SRH is correlated with health outcomes across immigrant generations. In related work, Antman, Duncan, and Trejo (2016) use several arguably more-objective health measures to show that ethnic attritors, defined as children not identified as Mexican American despite having at least one parent identified as Mexican American, are closer to non-Hispanic whites on several measures of health. Those results, using a broader set of health outcomes, are consistent with the results presented here, but are limited by the fact that data sets with a richer set of health outcomes only allow for ethnic attrition measures based on parental ethnic self-identification. In contrast, the CPS used in this paper contains information on parental place of birth, thus allowing for a more accurate method of measuring ethnic attrition, and allowing us to precisely identify $3^{\text {rd }}$ generation immigrants. Thus, this paper addresses the limitations of the earlier work and, taken together, both studies provide a more complete picture of the impact of ethnic attrition on measured health disparities.

Another important caveat to note is that we can only objectively trace immigrant generations as far back as data allow us to link individuals with objective measures of ancestry such as parents' place of birth and grandparents' place of birth, which we can obtain for children that still reside with their parents. As we show that ethnic attrition mainly affects immigrants at the $3^{\text {rd }}$ and higher generations, this means that in most of the paper we analyze health disparities 
between immigrant children and native children, and then investigate the role of ethnic attrition in explaining that difference. This marks another area of contribution for this paper, as most studies of immigrant health disparities focus exclusively on adults. However, our focus on children may also explain why we find no clear evidence of an immigrant health advantage, nor a distinct disadvantage among Mexican-identified children after controlling for socioeconomic status, relative to non-Hispanic white children in our sample. Nevertheless, since our goal is to understand the implications of ethnic attrition for measured health disparities, we are still able to relate these findings back to a sample of adult immigrants and thus contribute to the broader immigrant health literature. To this end, our analysis suggests that both the $1^{\text {st }}$ generation health advantage and the health disadvantage of later-generation Mexican adults (relative to non-Hispanic whites) are substantially overstated.

Our paper contributes to an emerging literature within economics on ethnic identity and how it relates to immigrant assimilation (Zimmermann 2007; Bisin and Verdier 2011; Constant and Zimmermann 2013). This literature has developed measures of ethnic identity (Constant and Zimmermann 2008; Constant, Gataullina, and Zimmermann 2009), investigated the determinants of identity formation and persistence (Bisin and Verdier 2000; Manning and Roy 2010; Masella 2011; Galli and Russo 2019), and analyzed the consequences of ethnic identity for the socioeconomic integration of immigrants and their descendants (Pendakur and Pendakur 2005; Constant, Roberts, and Zimmermann 2009; Constant and Zimmermann 2009; Bisin, Patacchini, Verdier, and Zenou 2011). This work recognizes the complexity and endogeneity of identity and suggests mechanisms through which ethnic identification could be associated with both observed and unobserved characteristics of individuals. Building on these insights, our paper highlights the complications that intergenerational shifts in ethnic identify can create for measuring the 
socioeconomic progress of later-generation descendants of immigrants. Our empirical analysis illustrates how such complications play out when attempting to track the health of Mexican Americans across immigrant generations.

The remainder of this paper proceeds as follows. Section II describes the data used in the analysis and presents conventional estimates of health disparities across immigrant generations and ethnic groups as they might be displayed in the literature relying on measures of selfidentification. Section III presents our empirical analyses, which describe how health outcomes for Mexican Americans vary by the nativity and ethnic origins of their ancestors, whether they come from families with mixed ethnic backgrounds, and whether they choose to subjectively identify as Mexican. A discussion of the bias introduced by ethnic attrition follows. Section IV concludes.

\section{DATA}

The data we use come from the 1996-2017 Current Population Survey (CPS) March Supplement. While the CPS is largely regarded as a labor force survey, covering standard questions about labor force participation and employment outcomes, it also collects important demographic information about respondents and household members that facilitate the analyses below. As mentioned above, we focus our analysis on Mexicans, the largest group of countryspecific immigrants to the U.S. (Lopez and Bialik 2017). ${ }^{4}$

\section{II.A. Measuring Health Status}

\footnotetext{
${ }^{4}$ Duncan and Trejo $(2016,2017)$ investigate ethnic attrition among other Hispanic groups and find similar patterns of educational selectivity across all Hispanic origin groups, but precise estimates of the magnitude of the implied biases is thwarted by the very small sample sizes of the non-Mexican groups. While this evidence suggests that health selectivity patterns are likely to be similar across Hispanic-origin groups as well, in practice, the small sample sizes associated with other Hispanic immigrants in the CPS limit our ability for precise comparisons with the Mexicanorigin group.
} 
With regard to health outcomes, the March Supplement collects information on self-rated health $(\mathrm{SRH})$, a measure that is widely used in the literature on immigrant health outcomes (Acevedo et al. 2010, Antecol and Bedard 2006, Riosmena et al. 2012). Specifically, respondents are asked to rank the subject's health on a 5-point scale indicating excellent, very good, good, fair, or poor health status. We follow the literature in assigning a poor health indicator equal to one if the respondent indicates poor or fair health and equal to zero if the respondent reports that health is good, very good, or excellent. ${ }^{5}$ Of course, there are understandable concerns about the selfrated health outcome, most notably that it reflects the respondent's subjective view of health, and thus may differ from objective health status. Nevertheless, it remains widely used throughout the health literature and has been shown to track results using more objective health outcomes such as obesity/body mass index (Antecol and Bedard 2006), predict future disability (Idler and Kasl 1995), and serve as an even better indicator of subsequent mortality than more complex health indicators (Kuhn et al. 2006). Its robust relationship with mortality in particular, documented in a wide variety of settings and replicated in numerous studies, suggests that SRH provides an important dimension of health not captured by other measures (Idler and Benyamini 1997).

At the same time, important questions surround the use of SRH in the current context. First, for reasons discussed below, our analyses focus on children ages 17 and younger. Given their youth, children are naturally less likely to suffer from functional decline and mortality observed in the older populations that have comprised the primary focus in most studies on the link between SRH and health status. Nevertheless, Case, Lubotsky and Paxson (2002) show a positive correlation between children's poor health outcomes and a wide variety of chronic health

\footnotetext{
${ }^{5}$ We follow the shorthand, common in the literature, of describing this outcome as a poor health indicator, although, as noted above, it also includes those reported to be in fair health. Typically the literature constructs the SRH measure as a binary measure of health status, reflecting the fact that indicators for poor or fair health in particular are good predictors of subsequent health outcomes such as mortality (Wolinsky and Johnson 1992).
} 
problems, conditional on parental income. This includes conditions such as epilepsy, kidney disease, asthma, diabetes and mental retardation, which are likely to be more objective health measures.

A related concern with SRH given our focus on children is that the latter are not responding to the survey themselves, and thus "self-rated health" in our study of children should be understood as health reported by the household respondent, typically a parent or adult caregiver. Nevertheless, ancillary studies using data on parent's and children's reports of children's health indicate that individual measures of health status are not statistically different based on whether the report is coming from a child or a parent (Case, Lubotsky, and Paxson 2002). Thus, we follow the practice of denoting health as "self-rated" although an adult respondent is reporting health for children and argue that this is likely to be close to the health status of the children were they responding for themselves.

Another concern regarding SRH in the current context is that the immigrant population may use a different set of factors to assess health than the native born population. For instance, Finch, et al. (2002) show that the association between SRH and subsequent mortality is mediated by acculturation measures such as years in the U.S. A related concern is that differences between the SRH of immigrants and natives may actually reflect language of interview, as prior studies have documented discrepancies in the translation of the SRH categories that may result in a downward-bias in SRH among Latinos (Viruell-Fuentes, et al. 2011). However, since the focus of our paper is ethnic attrition, a phenomenon that we will show is primarily observed at higherorder immigrant generations born in the U.S., systemic cultural differences in SRH reporting are much less likely to be salient factors explaining our results. Similarly, Krogstad, Stepler, and 
Lopez (2015) show that the overwhelming majority of U.S.-born Latinos are proficient in English, and thus Spanish translation of SRH is also not likely to play a major role underlying our findings.

Nevertheless, we can address the above concerns with SRH using a similar approach to Case, Lubotsky and Paxson (2002). In supplementary analysis reported in Appendix Table A1, we use the National Health Interview Survey (NHIS) to regress an indicator for poor/fair self-rated health on a wide range of health outcomes available in that data set. Thus, we can confirm that poor self-rated health is indeed highly correlated with more objective measures of health specific to children, including, but not limited to, having a chronic condition, developmental delay, learning disorder, missed school days, allergy, asthma, or other health limitation, even after controlling for language of interview. ${ }^{6}$ Ideally, Table A1 would estimate the correlation between SRH and health conditions for ethnic attritors and non-attritors within each generation, defined using grandparents' place of birth, but that is not possible because that information is not available in the NHIS. However, the positive correlation between poor health status and other poor health indicators among children clearly holds for $1^{\text {st }}$ and higher-order generations of Mexican immigrants, as well as non-Hispanic whites, suggesting that our findings on poor self-rated health are not simply an artifact of cultural factors which immigrants may use to grade their health status and that of their children. ${ }^{7}$ Based on descriptive statistics not reported here, we can also confirm that the extent of

\footnotetext{
${ }^{6}$ One important limitation of these alternative health measures, as with almost all health outcomes available in largescale data sets, is that they are self-reported, and thus potentially subject to measurement error biases. Nevertheless, we argue that these are likely to be smaller in magnitude than those associated with SRH, especially for those measures that are closely linked with an objective health condition (e.g. low birth weight). If one assumes that these measurement error biases reflect measures of acculturation to U.S. norms, we might also expect them to result in understated differences between higher-order immigrants and non-Hispanic whites.

${ }^{7}$ While Table A1 shows that low birth weight, which has been linked with smoking during pregnancy for higher-order immigrants (Giuntella 2016, 2017), displays a statistically significant correlation with SRH, it should be noted that the rest of the health outcomes in Table A1 cannot be strictly linked with risky behaviors. This limits our capacity to investigate the extent to which cultural assimilation and intermarriage can be linked with poor health outcomes for higher-order immigrant generations by way of risky health behaviors, as has been explored elsewhere in the literature (Giuntella 2016, 2017; Edwards and Goldstein 2018). Nevertheless, as the focus of this paper is on documenting the impact of ethnic attrition on health outcomes using the CPS, we return in the body of the paper to focusing on SRH
} 
ethnic attrition found in the NHIS sample is similar to that found in the CPS sample used in the main results section below. This suggests that the pattern of correlation between ethnic attrition and health outcomes is likely to be similar across the two data sets as well.

In addition to this supplementary evidence showing the link between SRH and objective health outcomes, Antman, Duncan, and Trejo (2016) use the NHIS to show that ethnic attritors, defined as children not identified as Mexican American despite having at least one parent identified as Mexican American, are closer to non-Hispanic whites on several measures of health, including low birth weight, obesity, and having an acute health condition or activity limitation. Ethnic attritors also more closely resemble non-Hispanic whites in terms of self-rated health. This is further evidence suggesting that self-rated health is likely to correlate well with more objective health measures for the population we focus on in this paper.

While the NHIS affords the luxury of a broader set of health outcomes, the measure of ethnic attrition available in that data set is limited by parental self-identification. This puts the NHIS at a significant disadvantage to the CPS used in the body of this paper, which allows us to leverage information on parents' place of birth as described below. Nevertheless, the supplementary evidence using the NHIS reviewed above suggest that the poor SRH outcome available in the CPS, though not ideal, can be viewed as a reasonable proxy for true poor health status in the population under study.

\section{II.B. Identifying Mexican Generations}

As mentioned above, the vast research on immigrant health and the Hispanic Health Paradox in particular has almost universally relied on self-reported ethnicity to identify the

and leave analysis of the link between ethnic attrition, risky behaviors, and resultant health outcomes for future research. 
descendants of Hispanic immigrants. From this perspective, individuals are identified as Hispanic if they respond affirmatively to the Hispanic origin question which asks respondents if they are Hispanic, Spanish, or Latino. ${ }^{8}$ Respondents that answer affirmatively are then asked with which Hispanic sub-group they identify. For instance, Mexican immigrants and their descendants are identified based on whether they identify themselves as Mexican on the Hispanic origin question. Foreign-born individuals are identified as $1^{\text {st }}$ generation immigrants, U.S.-born individuals with at least one foreign-born parent are identified as $2^{\text {nd }}$ generation immigrants, and U.S.-born individuals with no foreign-born parents are identified as $3^{\text {rd }}+$ generation immigrants. Thus, assimilation and intergenerational progress are tracked across generations of individuals who identify as Mexican, ignoring the possibility that some individuals with Mexican ancestry may not identify themselves as Mexican.

To make these notions concrete, Table 1 presents the percentage of 20-64 year-old adults reported to have poor health status as they might be presented in the literature relying on measures of ethnic self-identification. Comparing the health outcomes of $3^{\text {rd }}+$ generation non-Hispanic whites (column 4) with $3^{\text {rd }}+$ generation self-identified Mexicans (column 3) illustrates the perceived problem of incomplete intergenerational integration: only 9.31 percent of $3^{\text {rd }}+$ generation non-Hispanic white men are in poor health while the analogous statistic for $3^{\text {rd }}+$ generation Mexican men is 12.18. Similarly, comparing the health outcomes of $1^{\text {st }}$ generation Mexican immigrants (column 1) with $3^{\text {rd }}+$ generation self-identified Mexicans (column 3) illustrates the perceived puzzle of $1^{\text {st }}$ generation health advantage: only 9.57 percent of $1^{\text {st }}$ generation Mexican male immigrants are found to be in poor health while 12.18 percent of $3^{\text {rd }}+$

\footnotetext{
${ }^{8}$ It should be noted that surveys typically ask one respondent to report the racial and ethnic identities of all individuals within the household. We follow the common practice in the literature of describing this as "self-reported" identity, though, to be clear, this may be the identity of the individual as viewed by close family or household members.
} 
generation Mexican men are in poor health. Importantly, both of these gaps hinge on unbiased estimation of the health status of $3^{\text {rd }}+$ generation men. This paper investigates the extent to which selective ethnic attrition may skew those estimates, thus biasing the comparison of health outcomes across generations and between ethnic groups. While a higher percentage of women report poor health status, similar comparisons can be made for Mexican women across generations and between self-identified ethnic groups, though in some cases the magnitude of the gaps are substantially smaller.

A typical question raised in the literature on immigrant health is whether these disparities can be explained by differences in observable characteristics - at a minimum age, but also SES indicators such as educational attainment. Importantly, the regressions that investigate this question should not be interpreted as causal, as they only indicate whether the correlations between immigrant generation, ethnicity, and health persist after accounting for these important differences. We reproduce this style of regressions in Table 2, where the dependent variable is an indicator for poor or fair health, and the sample includes $1^{\text {st }}, 2^{\text {nd }}$, and $3^{\text {rd }}+$ generation Mexicans as well as $3^{\text {rd }}+$ generation non-Hispanic whites (the reference group). As the latter are mutually exclusive and exhaustive categories, the estimates in columns (1) and (4) generate the raw differences across groups and can be used to reproduce the summary statistics from Table 1. Thus, we can confirm that $3^{\text {rd }}+$ generation Mexican men are 2.87 percentage points more likely to be in poor health than $3^{\text {rd }}+$ generation non-Hispanic white men, an estimate that is statistically significant at the 1 percent level. Columns (2) and (5) add in basic controls such as age, age squared, and a set of dummy variables for survey year and location. Additionally, columns (3) and (6) follow the literature by controlling for years of education as a measure of SES. Here we find that $3^{\text {rd }}+$ generation Mexican men are 2.20 percentage points more likely to be in poor health than $3^{\text {rd }}+$ generation non-Hispanic 
white men, thus indicating that this gap cannot be fully explained by differences in observable characteristics. At the same time, $3^{\text {rd }}+$ generation Mexican men are 8.11 percentage points (.0220-.0591) more likely to be in poor health than $1^{\text {st }}$ generation Mexican male immigrants, suggesting that the puzzle of $1^{\text {st }}$ generation health advantage is only exacerbated by accounting for differences in SES.

Interestingly, the puzzle of $1^{\text {st }}$ generation advantage also rules out one possible explanation for the gap between later-generation Mexicans and non-Hispanic whites: $3^{\text {rd }}+$ generation Mexicans are not in worse health than $3^{\text {rd }}+$ generation non-Hispanic whites because unhealthy Mexicans arrive in the U.S. In fact, after controlling for socioeconomic status, we see that $1^{\text {st }}$ generation Mexicans immigrants are actually less likely to be in poor health than non-Hispanic whites (point estimate -.0591 for men). More importantly, the evidence presented here suggests that something is happening across immigrant generations in the U.S. that is making the descendants of Mexican immigrants less healthy, or at least appear to be less healthy. The remainder of this paper investigates the extent to which selective ethnic attrition skews our perception of that phenomenon.

Throughout the paper we use the following definitions to classify immigrant generation based on more objective information on place of birth of parents and grandparents. ${ }^{9} 1.5$ generation Mexicans are children born in Mexico. $2^{\text {nd }}$ generation Mexicans are U.S.-born and have at least one parent born in Mexico. $3^{\text {rd }}$ generation Mexicans are U.S.-born, have two U.S.-born parents, and have at least one grandparent born in Mexico. ${ }^{10}$ Finally, $4^{\text {th }}+$ generation Mexicans are U.S.-

\footnotetext{
${ }^{9}$ While we argue that antecedents' place of birth is a more objective measure of ancestry than self-reported ethnic identity, it should be noted that place of birth is also self-reported, and thus may also be subject to reporting biases. For instance, children of intermarried parents may be less likely to have Mexican grandparents listed in the survey, and thus appear to the researcher to be non-Hispanic white. As we expect these additional levels of unobserved ethnic attrition will operate in the same direction as the patterns of ethnic attrition we do observe, any biases resulting from failures to report Mexican ancestry make it less likely that we observe differences between Mexicans and non-Hispanic whites. As a result, our estimates of the impact of ethnic attrition on measured health disparities are likely to be understated.

${ }^{10} \mathrm{We}$ emphasize that this is the "exact" $3^{\text {rd }}$ generation as opposed to $3^{\text {rd }}$ generation and higher $\left(3^{\text {rd }}+\right)$.
} 
born, have two U.S.-born parents, have no grandparents born in Mexico, and have at least one parent who identifies as Mexican on the Hispanic origin question. ${ }^{11}$ As a comparison, $4^{\text {th }}+$ generation whites have no parents or grandparents who are foreign born, and themselves and both parents are identified as non-Hispanic on the Hispanic origin question and white only on the race question.

The CPS provides information on the country of birth of an adult respondent's parents, but not of his or her grandparents. Unfortunately, this makes it impossible for us to construct an objective measure of $3^{\text {rd }}$ and $4^{\text {th }}+$ generation Mexican adults. However, by linking children to their parents' records, we are able to identify the country of birth of a child's grandparents. For this reason, the analysis sample in the remainder of the paper is limited to children ages 17 and younger living in intact families at the time of the survey, since information on parents and grandparents on both sides of an individual's family are only available for this group. ${ }^{12}$ While our focus on children is necessary due to data limitations, it also means this study makes another important contribution to the literature on immigrant advantage and intergenerational health which typically focuses on adult health outcomes. ${ }^{13}$ However, the fact that the immigrant children we observe

\footnotetext{
${ }^{11}$ Some might describe this as the Mexican ancestry population more generally, as their specific immigrant generation is unclear. Its reliance on self-reported ethnic identity also raises concerns that estimates of health disparities involving this group may reflect endogeneity biases associated with levels of acculturation that affect health outcomes, as well as self-reported identities, of parents and children. Nevertheless, our use of the $4^{\text {th }}+$ generation terminology and comparison group parallels the literature's broad use of the " $3{ }^{\text {rd }}+$ " generation described above, and as with the latter measure will tend to underestimate ethnic attrition due to its reliance on parental self-identification. While the goal of this exercise is purely descriptive, our contribution here is to take this somewhat nebulous concept back one full generation.

${ }^{12}$ Our focus on children also means that our notion of "self-reported" identity is actually reported by the household respondent, typically a parent or adult caregiver. We view this response as likely to be consistent with the child's own ethnic identity at the time of the survey, since parents are important shapers of their children's identities. In any case, we expect that parental reporting likely yields an underestimate of ethnic attrition relative to asking children their own ethnic identities as adults once they have established households separate from their parents. Duncan and Trejo (2011a, Table 9) show that children's observed rates of Mexican identification in CPS data do not seem to vary systematically with which household member answered the CPS questionnaire (father, mother, or other household member) and with which parent provides the child's Mexican origins (father, mother, or both).

${ }^{13}$ Hamilton et al. (2011) provide a detailed analysis of how four common child health conditions vary by immigrant generation and race/ethnicity. They mention ethnic attrition as a potential explanation for some of the observed generational patterns, but their data do not allow them to investigate this issue empirically.
} 
came to the U.S. at an early age suggests they are likely to display health outcomes much closer to their U.S.-born counterparts compared with immigrants who arrived as adults. This caveat is further complicated by the fact that children are generally less likely than adults to be in poor health. As a result, it is not obvious that we should expect to see the same story of declining immigrant advantage which we observed for adults in Table 1. Nevertheless, we can still examine the role of selective ethnic attrition in biasing estimates of health status for U.S.-born Mexicans. As we presume any health differentials will be compounded over the life course, we expect that any biases observed here are likely to be understated compared with estimates we might obtain if it were possible to observe ethnic attrition in a sample of $3^{\text {rd }}+$ generation adults. ${ }^{14}$

\section{RESULTS}

Table 3 begins by documenting the extent of ethnic attrition of the children in our sample and linking this with whether their parents intermarried, that is whether they have Mexican ethnicity on one or both sides of the family. The definition of Mexican ethnicity on one side of the family is consistent across all generations. For example, a child has Mexican ethnicity on his father's side of the family if any of the following are true: (1) the child has a paternal grandparent who was born in Mexico; (2) the child's father was born in Mexico; or (3) the child's father selfidentifies as Mexican.

As can be seen from Table 3, one important empirical result is that Mexican identification is strongly linked with intermarriage. Across all generations, Mexican identification is almost universal (97\% to $99 \%$ ) among children of endogamous marriages, that is, those children with Mexican ethnicity on both sides of the family. In contrast, with the exception of " 1.5 generation"

\footnotetext{
${ }^{14}$ While it is possible, strictly speaking, to analyze the selectivity of ethnic attrition in our sample of $2^{\text {nd }}$ generation adults, ethnic attrition rates are very small for this group (less than 8 percent), perhaps unsurprisingly since they are the children of immigrants.
} 
Mexicans who are immigrants themselves, rates of ethnic identification are far lower (61\% to 68\%) for individuals with Mexican ethnicity on only one side of the family, that is, children of intermarriages between one Mexican and one non-Mexican. These patterns are also fairly consistent regardless of whether the Mexican ethnicity is on the father's or mother's side of the family.

It follows that the extent of ethnic attrition across generations will be closely linked with the extent of intermarriage across generations. This pattern is confirmed in Table 3, which mirrors findings elsewhere in the literature highlighting intermarriage as the primary source of ethnic attrition (Duncan and Trejo 2011, 2016, 2017; Antman, Duncan, and Trejo 2016). For instance, a very small share of $2^{\text {nd }}$ generation children have intermarried parents $(10.1 \%)$, that is, Mexican ethnicity on only one side of the family. Thus, it comes as no surprise that there is very little ethnic attrition at the $2^{\text {nd }}$ generation, and in fact, $94.45 \%$ of $2^{\text {nd }}$ generation children identify as Mexican. This is similar to the rate of Mexican identification among 1.5 generation children (97.50\%), who we emphasize are immigrants themselves, and who are almost exclusively the children of endogamous marriages (98.3\%). In contrast, rates of intermarriage are quite substantial for the parents of $3^{\text {rd }}$ and $4^{\text {th }}+$ generation children ( $44 \%$ and $61.3 \%$, respectively). Consequently, rates of Mexican identification are far lower for the latter groups ( $81.35 \%$ and $76.96 \%$, respectively). This implies that substantial shares of $3^{\text {rd }}$ and $4^{\text {th }}+$ generation children are not identified as Mexican (18.65\% and $23.04 \%$, respectively). ${ }^{15}$ Since ethnic attrition is a phenomenon primarily occurring at the $3^{\text {rd }}$ and higher generations, in the remainder of the paper, we limit our analysis of ethnic attrition to these groups.

\footnotetext{
${ }^{15}$ Further analysis, not reported here, confirms that ethnic attritors are not only attriting out of Mexican identity, but attriting out of Hispanic identity altogether. Fewer than 2 percent of children with Mexican ancestry identify as Hispanic, but not Mexican, at the $4^{\text {th }}+$ generation. Consequently, the results below documenting correlations with ethnic attrition out of Mexican identity are substantially similar if attrition is defined as attriting from Hispanic identity.
} 
Thus far, we have established that intermarriage rates are substantial at the $3^{\text {rd }}$ and higher generations and ethnic attrition is closely linked with parental intermarriage. ${ }^{16}$ We now proceed in connecting parental intermarriage with parental health. This is done in Table 4, which shows the percent of parents in poor health based on whether children have two Mexican parents (Mexican on both sides of the family) or one Mexican and one non-Mexican parent (Mexican on one side of the family). With regard to intermarriage, it is noteworthy that both fathers and mothers in intermarriages are less likely to be in poor health. For example, about $6 \%$ of fathers who are intermarried report poor SRH, whereas 8.55 to $9.76 \%$ of fathers who are not intermarried report poor SRH at the $3^{\text {rd }}$ and $4^{\text {th }}+$ generations, respectively. ${ }^{17}$ Thus, intermarriage between Mexicans and non-Mexicans appears to be selective on health. ${ }^{18}$

Table 5 completes the picture by linking parental health directly with children's ethnic identification. Since previous tables have already established the close connection between ethnic attrition and intermarriage, it should come as no surprise that the pattern of results look strikingly similar to Table 4. For the most part, health status is better for parents of those children who are not identified as Mexican (parents of ethnic attritors), compared with the parents of children that are identified as Mexican (parents of non-attritors). For instance, $8.29 \%$ of fathers of $4^{\text {th }}+$ generation children identified as Mexican report being in poor health compared with only $4.89 \%$

\footnotetext{
${ }^{16}$ While Table 3 confirms that the primary source of ethnic attrition in our sample is intermarriage, we emphasize that the analysis that follows does not restrict attention to sources of ethnic attrition resulting from intermarriage, but rather estimates the net effect of all sources of ethnic attrition on measured health disparities. Closer analysis of the determinants and implications of ethnic attrition, holding intermarriage constant, is limited by the relatively small numbers of ethnic attritors from endogamous marriages, but would be an interesting avenue for future research.

${ }^{17}$ In extended analysis not emphasized here, both the Mexican and non-Mexican spouse are likely to report better health. This is similar to the result from the assortative mating literature which finds that individuals are matched on measures of human capital such as education (Mare 1991; Pencavel 1998).

${ }^{18}$ While the link between health and intermarriage is suggestive of a mechanism that is selective on health, we acknowledge that this process may be muddled by simultaneity in mate selection and health choices, which may in turn affect our measures of SRH that are reported after marriage has occurred. As our intent is ultimately to establish correlations between health and ethnic attrition, we leave further exploration of this mechanism to future research.
} 
of fathers of $4^{\text {th }}+$ generation children not identified as Mexican. The same pattern is apparent for fathers of $3^{\text {rd }}$ generation children, albeit with a smaller gap (7.75\% versus $\left.5.58 \%\right)$. Assuming an intergenerational correlation in health status, this would suggest that ethnic attritors themselves are also likely to be in better health compared with non-attritors.

Table 6 addresses this question directly by documenting the percentage of children reporting poor health status by generation and ethnic identification. Importantly, we note that sample sizes are small and differences in point estimates are also small given the nature of the SRH outcome and the focus on children in our study. Thus, we do not aim to find statistically significant differences among our sample of children, only suggestive indications of differences in the broader population. With these caveats in mind, and as expected given the results from above, we find that the patterns displayed in Table 6 are consistent with the results from above: ethnic attrition is selective on the health of children, with the degree of selectivity varying by generation. $3^{\text {rd }}$ generation Mexican children who do not identify as Mexican are somewhat less likely to report being in poor health compared with $3^{\text {rd }}$ generation Mexican children who identify as Mexican ( $1.46 \%$ versus $1.74 \%$, respectively). Given this relatively small difference, the percent of $3^{\text {rd }}$ generation Mexicans estimated to be in poor health which includes all $3^{\text {rd }}$ generation Mexicans based on grandparents' place of birth $(1.69 \%)$ is close to the estimate which relies on Mexican self-identification $(1.74 \%)$. For the $4^{\text {th }}+$ generation, however, the gap in poor health status is somewhat larger for ethnic attritors versus non-attritors (1.44\% versus $1.82 \%$, respectively). As a result, the overall percentage of $4^{\text {th }}+$ generation Mexicans reported to be in poor health $(1.74 \%)$ is somewhat lower than the estimate based on self-identification $(1.82 \%) .{ }^{19}$ In short, as ethnic

\footnotetext{
${ }^{19}$ In additional results not presented here, we have used an alternative, more flexible, definition of $4^{\text {th }}+$ generation that includes individuals that are U.S.-born, have two U.S.-born parents, have no grandparents born in Mexico, and at least one parent who identifies as Hispanic on the Hispanic origin question. Those results are substantially similar to the
} 
attritors are positively selected on health, conventional estimates of health outcomes for higherorder immigrant generations make them appear to be in worse health than they actually are.

Table 6 also provides insight into how selective ethnic attrition might bias standard comparisons of health outcomes across generations of Mexican Americans and between Mexican Americans and non-Hispanic whites. ${ }^{20}$ Before discussing these results, it should be emphasized that the 1.5 generation immigrants in our sample came to the U.S. as children and are thus likely to display health outcomes much closer to those of U.S.-born children than, say, adults who were born in Mexico and migrated as adults. This caveat is compounded by the fact that in general children are less likely to be in poor health relative to adults and thus health disparities are likely to be understated for this group. As a result, for child self-rated health, as with other outcomes in the literature on immigrant health (Riosmena et al. 2012), we do not find a clear story of immigrant advantage. ${ }^{21}$ However, ultimately our interest is not in documenting immigrant advantage and assimilation gaps in the SRH of children specifically, but rather in using the sample of children to estimate the extent of ethnic attrition and the degree to which it is selective on health. While there are no studies to our knowledge that indicate how child SRH translates into adult SRH, if we reasonably presume that they are correlated we can use the Table 6 results to get a rough estimate of the magnitude of the effect ethnic attrition has on the adult patterns seen in Table 1. This may be a lower bound estimate if, for example, a parent's adult SRH is transmitted to her child, but this

results presented here, even after restricting the analysis to states that were historically linked with the Mexican-origin population, i.e. California, Illinois, and Texas.

${ }^{20}$ Owing to the smaller sample sizes, we consider outcomes for girls and boys together and do not examine the selectivity of ethnic attrition at the 1.5 and $2^{\text {nd }}$ generations, where rates of ethnic attrition are especially low.

${ }^{21}$ While data limitations prevent us from comparing 1.5 generation Mexicans with the populations from which they originated, the fact that we find no clear evidence of an immigrant health advantage for the children in the sample also suggests that there are not likely to be any clear patterns of positive migrant selection on health for immigrants that arrived as children. Future research could compare child migrants with children in Mexico to investigate this directly. 
is more likely to show up in adult SRH versus child SRH. To the extent that additional ethnic attrition occurs as children transition into adulthood, we might also regard this as an underestimate.

Thus, we use the results from Table 6 to obtain a rough approximation of the size of the bias due to ethnic attrition which could affect estimates of $1^{\text {st }}$ generation advantage and long-term integration for the adult population documented in Table 1. In particular, estimates for the $4^{\text {th }}+$ generation from Table 6 suggest that ethnic attrition is associated with an increased likelihood of reporting poor health status by $4.60 \%$ [(1.82-1.74)/1.74]. If the same effect were to apply to the $3^{\text {rd }}+$ generation adults in Table 1 , the corrected percentage of respondents reporting poor health status would be $11.64 \%(12.18 / 1.0460)$. This implies that the gap between $3^{\text {rd }}+$ and $1^{\text {st }}$ generation Mexicans is about $21 \%$ smaller (11.64-9.57 versus 12.18-9.57) than suggested by conventional estimates based on subjective measures of ethnic identification. Similar analysis implies that using more objective measures of ethnic identification would yield a reduction of about 19\% (11.649.31 versus $12.18-9.31$ ) in the health gap between $3^{\text {rd }}+$ generation Mexicans and $3^{\text {rd }}+$ generation whites. In other words, both the $1^{\text {st }}$ generation health advantage and the health disadvantage of later-generation Mexicans (relative to non-Hispanic whites) are substantially overstated. This bias stems from the relatively large difference in health status between ethnic attritors and nonattritors at the $4^{\text {th }}+$ generation.

Table 7 examines these health differentials further by investigating whether they survive after accounting for observable differences such as gender, age, and SES. ${ }^{22}$ To do this, we first estimate a regression on the sample of all groups noted in Table 6, where the dependent variable

\footnotetext{
${ }^{22}$ To be consistent with the literature, the SES controls include mother's and father's years of education and employment status (Antecol and Bedard , 2006). While the latter measure in particular is not included to estimate a causal relationship, it can be viewed as a control that may capture important differences across individuals, such as access to health care. In additional analysis not reported here, we have explored controlling for health insurance directly in analogous regressions on the population of children ages 14 and younger and found that it did not meaningfully affect the pattern of results.
} 
is an indicator for poor health status and the right-hand side includes a mutually exclusive and exhaustive set of dummy variables accounting for all of the categories featured at the top of Table 6 , with the exception of $4^{\text {th }}+$ generation non-Hispanic whites (the reference group). Thus, the estimates in column (1) can be used to reproduce the differences in health outcomes across the columns from Table 6 , and confirm that ethnic attritors at the $4^{\text {th }}+$ generation have health outcomes similar to those of $4^{\text {th }}+$ generation non-Hispanic whites (coefficient estimate 0.0020 ). Column (2) adds basic controls for gender, age, year, and location, with little change in the results: selfidentified Mexicans at the $4^{\text {th }}+$ generation are about 0.55 percentage points more likely to be in poor health relative to $4^{\text {th }}+$ generation non-Hispanic whites. However, this health differential is cut by more than half once we add controls for socioeconomic status (column 3), dropping the coefficient estimate on $4^{\text {th }}+$ generation self-identified Mexicans to a statistically insignificant 0.0026. Once we control for parental health characteristics (column 4), the difference between self-identified Mexicans and non-Hispanic whites disappears almost completely (coefficient estimate 0.0014). More importantly, the health differential between ethnic attritors and nonattritors at the $4^{\text {th }}+$ generation is not statistically significant after controlling for parental characteristics. This suggests that the relationship between health and ethnic attrition is driven by parental characteristics - the health differential between ethnic attritors and non-attritors effectively disappears once we control for those parental characteristics determining ethnic attrition.

\section{CONCLUSION}

This paper has investigated the role of ethnic attrition in biasing estimates of the health status of U.S.-born Mexicans. We find that at higher-order immigrant generations, ethnic attritors display better health outcomes than non-attritors and closer to those of non-Hispanic whites. This 
implies that estimates of health status which rely on ethnic self-identification make Mexican Americans appear to be in worse health than they actually are. As a result, standard evidence of incomplete integration, showing U.S.-born Mexicans in significantly worse health than nonHispanic whites, is significantly overstated. Similarly, these results suggest that failing to account for the relatively better health of ethnic attritors is likely to overstate any estimated $1^{\text {st }}$ generation health advantage which relies on self-reported ethnic identification.

Additionally, we find that once we control for parental health and SES, the health differential by ethnic attrition disappears, reinforcing the view that ethnic attrition is driven by parental characteristics. We also show that intermarried individuals are likely to be in better health, and are more likely to produce children that are not identified as Mexican who are also in better health. Together, this collection of results suggests that selective ethnic attrition, driven by parental characteristics that are culled through a process of selective intermarriage, biases our estimates of the health of U.S.-born Mexicans and thus skews our perceptions of immigrant advantage and intergenerational integration. This is consistent with earlier work (Antman, Duncan, and Trejo 2016) showing similar results applied to a broader range of health outcomes, but relying on a more limited measure of ethnic attrition across immigrant generations. Future work should investigate other measures of well-being used in the cultural assimilation literature, such as life satisfaction (Angelini, Casi, and Corazzini 2015), to assess the impacts of ethnic attrition on a wider set of outcomes.

While our estimates suggest that ethnic attrition is an important phenomenon overlooked by research studies that rely solely on subjective measures of lineage, an important caveat of this study is that data limitations inherent in the CPS restrict our analysis to self-rated health status on a sample of children. While we have shown that SRH is correlated with a wide array of health 
outcomes, future data collection efforts should increase the availability of objective variables documenting ancestral origins such as antecedents' places of birth, and link these with a wider set of objective health outcomes and health behaviors, thus facilitating research in this area. Despite these limitations, we have argued that our estimates of the magnitude of ethnic attrition and resulting biases are likely to be understated. Since the analysis here is limited to children, it is likely that our estimates of the impact of ethnic attrition on measured health disparities are likely to be underestimated because ethnic attrition rates are likely to be higher than what we observe here just as differences in health outcomes are likely to become all the more salient as children transition to adulthood. Consequently, we should expect the bias due to ethnic attrition that is present in current estimates of health differentials across immigrant generations and ethnic groups to be even larger in magnitude than what is suggested here. 
Conflict of Interest: The authors declare that they have no conflict of interest. 


\section{REFERENCES}

Acevedo-Garcia, Dolores, Jocelyn Pan, Hee-Jin Jun, Theresa L. Osypuk and Karen M. Emmons. 2005. "The Effect of Immigrant Generation on Smoking." Social Science and Medicine, 61:1223-1242.

Acevedo-Garcia, Dolores, Lisa M. Bates, Theresa L. Osypuk, and Nancy McArdle. 2010. “The Effect of Immigrant Generation and Duration on Self-rated Health among US Adults 20032007." Social Science and Medicine, 71: 1161-72.

Adler, Nancy E. and Joan M. Ostrove. 2006. "Socioeconomic Status and Health: What We Know and What We Don't." Annals New York Academy of Sciences, 896(1): 3-15.

Alba, Richard D., and Tariqul Islam. 2009. "The Case of the Disappearing Mexican Americans: An Ethnic-Identity Mystery." Population Research and Policy Review, 28(2): 109-21.

Antecol, Heather and Kelly Bedard. 2006. "Unhealthy Assimilation: Why Do Immigrants Converge to American Health Status Levels?” Demography, 43(2): 337-60.

Antman, Francisca and Brian Duncan. 2015. "Incentives to Identify: Racial Identity in the Age of Affirmative Action." Review of Economics and Statistics, 97(3): 710-13.

Antman, Francisca, Brian Duncan, and Stephen J. Trejo. 2016. "Ethnic Attrition and the Observed Health of Later Generation Mexican Americans." American Economic Review, 106(5): 467-71.

Angelini, Viola, Laura Casi, and Luca Corazzini. 2015. "Life Satisfaction of Immigrants: Does Cultural Assimilation Matter?” Journal of Population Economics, 28(3): 817-844.

Bates, Lisa M., Dolores Acevedo-Garcia, Margarita Alegría, and Nancy Krieger. 2008. "Immigration and Generational Trends in Body Mass Index and Obesity in the United States: Results of the National Latino and Asian American Survey, 2002-2003." American Journal of Public Health, 98(1): 70-77.

Bisin, Alberto; Patacchini, Eleonora; Verdier, Thierry; and Zenou, Yves. 2011. "Ethnic Identity and Labour Market Outcomes of Immigrants in Europe." Economic Policy, 26(65), pp. 57-86.

Bisin, Alberto, and Verdier, Thierry. 2000. “'Beyond the Melting Pot': Cultural Transmission, Marriage, and the Evolution of Ethnic and Religious Traits." Quarterly Journal of Economics, 115(3), pp. 955-88.

Bisin, Alberto, and Verdier, Thierry. 2011. "The Economics of Cultural Transmission and Socialization," in Jess Benhabib, Alberto Bisin, and Matthew O. Jackson, eds., Handbook of Social Economics, vol. 1A. Amsterdam: North Holland, pp. 339-416. 
Borjas, George J. 1994. “The Economics of Immigration.” Journal of Economic Literature, 32: $1667-1717$.

Bzostek, Sharon, Noreen Goldman, and Anne Pebley. 2007. "Why Do Hispanics in the USA Report Poor Health?" Social Science and Medicine, 65:990-1003.

Case, Anne, Darren Lubotsky, and Christina Paxson. 2002. "Economic Status and Health in Childhood: The Origins of the Gradient." American Economic Review, 92(5): 1308-34.

Constant, Amelie F.; Gataullina, Liliya; and Zimmermann, Klaus F. 2009. "Ethnosizing Immigrants." Journal of Economic Behavior and Organization, 69(3), pp. 274-87.

Constant, Amelie F.; Roberts, Rowan; and Zimmermann, Klaus F. 2009. "Ethnic Identity and Immigrant Homeownership." Urban Studies, 46(9), pp. 1879-98.

Constant, Amelie F., and Zimmermann, Klaus F. 2008. "Measuring Ethnic Identity and Its Impact on Economic Behavior." Journal of the European Economic Association, 6(2-3), pp. 424-33.

Constant, Amelie F., and Zimmermann, Klaus F. 2009. "Work and Money: Payoffs by Ethnic Identity and Gender." Research in Labor Economics, 29 (Ethnicity and Labor Market Outcomes, edited by Amelie F. Constant, Konstantinos Tatsiramos, and Klaus F. Zimmermann), pp. 3-30.

Constant, Amelie F., and Zimmermann, Klaus F. 2013. "Immigrants, Ethnic Identities and the Nation-State," in Amelie F. Constant and Klaus F. Zimmermann, eds., International Handbook on the Economics of Migration, Cheltenham, United Kingdom: Edward Elgar Publishing, pp. 259-275.

Duncan, Brian and Stephen J. Trejo. 2011a. "Intermarriage and the Intergenerational Transmission of Ethnic Identity and Human Capital for Mexican Americans." Journal of Labor Economics, 29(2): 195-227.

Duncan, Brian and Stephen J. Trejo. 2011b. "Who Remains Mexican? Selective Ethnic Attrition and the Intergenerational Progress of Mexican Americans" in David L. Leal and Stephen J. Trejo, eds., Latinos and the Economy: Integration and Impact in Schools, Labor Markets, and Beyond, New York: Springer, p. 285-320.

Duncan, Brian, and Stephen J. Trejo. 2016. "The Complexity of Immigrant Generations: Implications for Assessing the Socioeconomic Integration of Hispanics and Asians." NBER Working Paper No. 21982.

Duncan, Brian, and Stephen J. Trejo. 2017. "The Complexity of Immigrant Generations: Implications for Assessing the Socioeconomic Integration of Hispanics and Asians." Industrial and Labor Relations Review, 70(5): 1146-75. 
Escarce, Jose J., Leo S. Morales, and Ruben G. Rumbaut. 2006. "The Health Status and Health Behaviors of Hispanics" in Hispanics and the Future of America. Panel on Hispanics in the United States, Committee on Population, Division of Behavioral and Social Sciences and Education. Washington, DC: The National Academies Press.

Finch, Brian Karl, Robert A. Hummer, Maureen Reindl and William A. Vega. 2002. "Validity of Self-Rated Health Among Latino(a)s." American Journal of Epidemiology, 155(8): 755-59.

Galli, Fausto, and Russo, Giuseppe. 2019. "Immigration Restrictions and Second-Generation Cultural Assimilation: Theory and Quasi-Experimental Evidence." Journal of Population Economics, 32(1), pp. 23-51.

Giuntella, Osea. 2016. “Assimilation and Health: Evidence from Linked Birth Records of Secondand Third-Generation Hispanics.” Demography, 53(6): 1979-2004.

Giuntella, Osea. 2017. "Why Does the Health of Mexican Immigrants Deteriorate? New Evidence from Linked Birth Records." Journal of Health Economics, 54:1-16.

Hakimzadeh, Shirin and D’Vera Cohn. 2007. "English Usage Among Hispanics in the United States.” Pew Research Center, Washington, D.C.

Hamilton, Erin R., Jodi Berger Cardoso, Robert A. Hummer, and Yolanda C. Padilla. 2011. "Assimilation and Emerging Health Disparities among New Generations of U.S. Children." Demographic Research, 25: 783-818.

Hummer, Robert A., Daniel A. Powers, Starling G. Pullum, Ginger L. Gossman, and W. Parker Frisbie. 2007. "Paradox Found (Again): Infant Mortality Among the Mexican-Origin Population in the United States." Demography, 44(3): 441-57.

Idler, Ellen L. and Yael Benyamini. 1997. "Self-Rated Health and Mortality: A Review of Twenty-Seven Community Studies." Journal of Health and Social Behavior, 38(1): 2137.

Idler, Ellen L. and Stanislav V. Kasl. 1995. "Self-Ratings of Health: Do They Also Predict Change in Functional Ability?" Journal of Gerontology B Journal of Gerontology Psychological Sciences and Social Sciences, 50B (6): S344-S353.

Krogstad, Jens Manuel, Renee Stepler and Mark Hugo Lopez. 2015. "English Proficiency on the Rise among Latinos; U.S. Born Driving Language Changes." Pew Research Center, Washington, D.C.

Kuhn, Randall, Omar Rahman, and Jane Menken. 2006. "Survey measure of health: How well do self-reported and observed indicators measure health and predict mortality?" In Barney Cohen and Jane Menken, editors, Aging in Sub-Saharan Africa: Recommendations for Furthering Research. The National Academies Press, Washington, D.C. 
Lopez, Gustavo and Kristen Bialik. 2017. "Key Findings about U.S. Immigrants.” Pew Research Center. Available at http://www.pewresearch.org/fact-tank/2017/05/03/key-findingsabout-u-s-immigrants/.

Manning, Alan, and Roy, Sanchari. 2010. "Culture Clash or Culture Club? National Identity in Britain.” Economic Journal, 120(542), pp. 72-100.

Mare, Robert D. 1991. "Five Decades of Educational Assortative Mating." American Sociological Review, 56(1): 15-32.

Masella, Paolo. "National Identity and Ethnic Diversity." 2013. Journal of Population Economics, 26(2), pp. 437-54.

Motel, Seth and Eileen Patten. 2012. "The 10 Largest Hispanic Origin Groups: Characteristics, Rankings, Top Counties." Pew Research Center. Available at http://www.pewhispanic.org/2012/06/27/the-10-largest-hispanic-origin-groupscharacteristics-rankings-top-counties/.

National Research Council. 2006. Multiple Origins, Uncertain Destinies: Hispanics and the American Future, ed. Marta Tienda and Faith Mitchell. Washington, DC: The National Academies Press.

Palloni, Alberto and Elizabeth Arias. 2004. "Paradox Lost: Explaining the Hispanic Adult Mortality Advantage." Demography, 41(3): 385-415.

Pastor, Patricia N., Cynthia A. Reuben, and Catherine R. Duran. 2015. "Reported Child Health Status, Hispanic Ethnicity, and Language of Interview: United States, 2011-2012." National Health Statistics Report, No. 82. Hyattsville, MD: National Center for Health Statistics.

Pencavel, John. 1998. "Assortative Mating by Schooling and the Work Behavior of Wives and Husbands." American Economic Review, 88(2): 326-29.

Pendakur, Krishna, and Pendakur Ravi. 2005. "Ethnic Identity and the Labour Market." Research on Immigration and Integration in the Metropolis, Working Paper Series No. 05-10.

Riosmena, Fernando, Bethany G. Everett, Richard G. Rogers, Jeff A. Dennis. 2015. "Negative Acculturation and Nothing More? Cumulative Disadvantage and Mortality during the Immigrant Adaptation Process among Latinos in the U.S." International Migration Review, 49(2): 443-78.

Riosmena, Fernando, Rebeca Wong, and Alberto Palloni. 2012. "Migration Selection, Protection, and Acculturation in Health: A Binational Perspective on Older Adults." Demography, 50: 1039-64. 
Rosenberg, H.M., J.D. Maurer, P.D. Sorlie, N.J. Johnson, M.F. MacDorman, D.L. Hoyert, J.F. Spitler, C.S. Scott. 1999. "Quality of Death Rates by Race and Hispanic Origin: A Summary of Current Research, 1999." Vital Health Statistics, Series 2 (128), Hyattsville, MD: National Center for Health Statistics.

Singh, Gopal K. and Mohammad Siahpush. 2002. "Ethnic-Immigrant Differentials in Health Behaviors, Morbidity, and Cause-Specific Mortality in the United States: An Analysis of Two National Databases." Human Biology, 74(1): 83-109.

Smith, James P. 2003. "Assimilation Across the Latino Generations." American Economic Review, 93(2): 315-19.

Tavernise, Sabrina. 2013, May 18. "The Health Toll of Immigration." The New York Times. Accessed September 9, 2014. Available online at http://www.nytimes.com/2013/05/19/health/the-health-toll-ofimmigration.html?pagewanted=all\&_r $=0$

Viruell-Fuentes, Edna A, Jeffrey D. Morenoff, David R. Williams, and James S. House. 2011. "Language of Interview, Self-Rated Health and the Other Latino Health Puzzle." American Journal of Public Health, 101(7):1306-13.

Wolinsky, Frederic D. and Robert J. Johnson. 1992. "Perceived Health Status and Mortality among Older Men and Women.” Journal of Gerontology, 47(6): S304-S312.

Zimmermann, Klaus F. 2007. "Migrant Ethnic Identity: Concept and Policy Implications." Ekonomia, 10(1): 1-17. 
Table 1: Percentage of adults aged 20-64 reporting poor health status, by Mexican generation

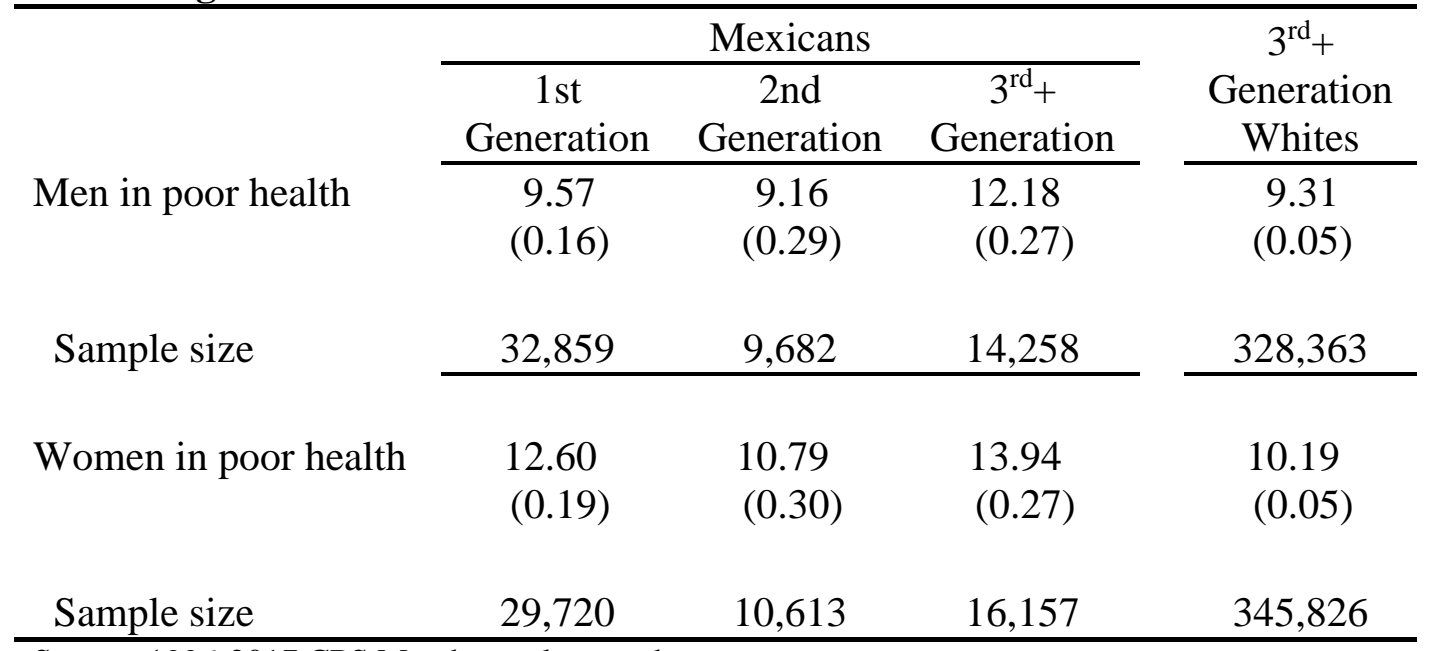

Source: 1996-2017 CPS March supplement data.

Note: Standard errors are shown in parentheses. The sample includes men and women ages 2064. Mexicans are identified by the Hispanic origin question. $3^{\text {rd }}+$ generation whites are nonHispanic white only. 
Table 2: Poor health regressions for Mexican generations relative to $3^{\text {rd }}+$ generation whites, by gender

\begin{tabular}{|c|c|c|c|c|c|c|}
\hline & \multicolumn{3}{|c|}{ Men } & \multicolumn{3}{|c|}{ Women } \\
\hline & $(1)$ & (2) & (3) & (4) & $(5)$ & (6) \\
\hline $1^{\text {st }}$ generation Mexican & $\begin{array}{l}.0026 \\
(.0017)\end{array}$ & $\begin{array}{l}.0250^{* * * *} \\
(.0018)\end{array}$ & $\begin{array}{l}-.0591^{* * *} \\
(.0020)\end{array}$ & $\begin{array}{l}.0240^{* * * *} \\
(.0019)\end{array}$ & $\begin{array}{l}.0411^{* * *} \\
(.0020)\end{array}$ & $\begin{array}{l}-.0525^{* * *} \\
(.0022)\end{array}$ \\
\hline $2^{\text {nd }}$ generation Mexican & $\begin{array}{l}-.0015 \\
(.0030)\end{array}$ & $\begin{array}{l}.0316^{* * * *} \\
(.0031)\end{array}$ & $\begin{array}{l}.0069^{*} \\
(.0031)\end{array}$ & $\begin{array}{c}.0059^{*} \\
(.0030)\end{array}$ & $\begin{array}{l}.0367^{* * * *} \\
(.0031)\end{array}$ & $\begin{array}{l}.0092^{* *} \\
(.0031)\end{array}$ \\
\hline $3^{\text {rd }}+$ generation Mexican & $\begin{array}{l}.0287^{* * *} \\
(.0025)\end{array}$ & $\begin{array}{l}.0459^{* * *} \\
(.0026)\end{array}$ & $\begin{array}{l}.0220^{* * *} \\
(.0026)\end{array}$ & $\begin{array}{l}.0375^{* * *} \\
(.0025)\end{array}$ & $\begin{array}{l}.0505^{* * *} \\
(.0026)\end{array}$ & $\begin{array}{l}.0228^{* * *} \\
(.0026)\end{array}$ \\
\hline Years of education & & & $\begin{array}{l}-.0186^{* * *} \\
(.0002)\end{array}$ & & & $\begin{array}{l}-.0206^{* * *} \\
(.0002)\end{array}$ \\
\hline Basic controls & No & Yes & Yes & No & Yes & Yes \\
\hline Average poor health & .0943 & .0943 & .0943 & .1054 & .1054 & .1054 \\
\hline Sample size & 385,162 & 385,162 & 385,162 & 402,316 & 402,316 & 402,316 \\
\hline
\end{tabular}

Source: 1996-2017 CPS March supplement data.

Note: Standard errors are shown in parentheses. The sample includes $1^{\text {st }}, 2^{\text {nd }}$, and $3^{\text {rd }}+$ generation Mexicans and $3^{\text {rd }}+$ generation non-Hispanic whites (the reference group), ages 20-64. Mexicans are identified by the Hispanic origin question. Each column reports estimates from a separate ordinary least squares regression of the form: $H_{i}=\beta I_{i}+X_{i} \pi+\varepsilon_{i}$, where $H_{i}=1$ if individual $i$ has poor/fail health, and $I_{i}$ is a vector including the following dummy variables: $1^{\text {st }}$ Generation Mexican, $2^{\text {nd }}$ Generation Mexican, $3^{\text {rd }}+$ Generation Mexican. Basic controls include age, age squared, and dummy variables for survey year, division of the country, individual states NY, NJ, IL, FL, TX, NM, AZ, CA, and urban area. 
Table 3: Mexican identification of children ages 17 and younger, by source of Mexican ethnicity

\begin{tabular}{|c|c|c|c|c|}
\hline & $\begin{array}{c}1.5 \\
\text { Generation } \\
\end{array}$ & $\begin{array}{c}\text { 2nd } \\
\text { Generation }\end{array}$ & $\begin{array}{c}\text { 3rd } \\
\text { Generation }\end{array}$ & $\begin{array}{c}\text { 4th+ } \\
\text { Generation }\end{array}$ \\
\hline \multicolumn{5}{|l|}{ Percent with Mexican ethnicity on: } \\
\hline Both sides of the family & 98.3 & 89.9 & 56.0 & 38.7 \\
\hline One side of the family & 1.3 & 10.1 & 44.0 & 61.3 \\
\hline Father's side only & 0.3 & 5.4 & 22.9 & 30.7 \\
\hline Mother's side only & 1.0 & 4.7 & 21.1 & 30.7 \\
\hline Either side of the family & $99.6^{+}$ & 100.0 & 100.0 & 100.0 \\
\hline \multicolumn{5}{|l|}{ Percent identified as Mexican with: } \\
\hline Mexican on both sides of the family & $\begin{array}{r}98.00 \\
(.19)\end{array}$ & $\begin{array}{r}97.43 \\
(.10)\end{array}$ & $\begin{array}{r}96.96 \\
(.30)\end{array}$ & $\begin{array}{r}98.59 \\
(.18)\end{array}$ \\
\hline Mexican on one side of the family & $\begin{array}{l}85.71 \\
(4.21)\end{array}$ & $\begin{array}{r}67.92 \\
(.86)\end{array}$ & $\begin{array}{r}61.46 \\
(.96)\end{array}$ & $\begin{array}{r}63.32 \\
(.59)\end{array}$ \\
\hline Mexican on father's side only & $\begin{array}{c}75.00 \\
(11.18)\end{array}$ & $\begin{array}{l}66.58 \\
(1.19)\end{array}$ & $\begin{array}{l}63.11 \\
(1.32)\end{array}$ & $\begin{array}{r}61.64 \\
(.84)\end{array}$ \\
\hline Mexican on mother's side only & $\begin{array}{l}88.89 \\
(4.32)\end{array}$ & $\begin{array}{l}69.47 \\
(1.25)\end{array}$ & $\begin{array}{l}59.66 \\
(1.40)\end{array}$ & $\begin{array}{r}65.00 \\
(.83)\end{array}$ \\
\hline All & $\begin{array}{r}97.50 \\
(.21)\end{array}$ & $\begin{array}{r}94.45 \\
(.13)\end{array}$ & $\begin{array}{r}81.35 \\
(.51)\end{array}$ & $\begin{array}{r}76.96 \\
(.40)\end{array}$ \\
\hline Sample size & 5,328 & 29,185 & 5,867 & 10,830 \\
\hline \multicolumn{5}{|c|}{$\begin{array}{l}\text { Source: 1996-2017 CPS March supplement data. } \\
\text { Note: Standard errors are shown in parentheses. The samples include U.S.- and Mexican-born children ages } 17 \text { and below } \\
\text { who live in intact families. } 1.5 \text { generation Mexicans are children born in Mexico. } 2^{\text {nd }} \text { generation Mexicans are U.S.-born and } \\
\text { have at least one parent born in Mexico. } 3^{\text {rd }} \text { generation Mexicans are U.S.-born, have two U.S.-born parents, and at least one } \\
\text { grandparent born in Mexico. } 4^{\text {th }}+\text { generation Mexicans are U.S.-born, have two U.S.-born parents, have no grandparents born } \\
\text { in Mexico, and at least one parent who identifies as Mexican on the Hispanic origin question. }\end{array}$} \\
\hline
\end{tabular}


Table 4: Poor health status of parents of children ages 17 and younger, by source of Mexican ethnicity

\begin{tabular}{|c|c|c|}
\hline & $\begin{array}{c}\text { 3rd } \\
\text { Generation }\end{array}$ & $\begin{array}{c}\text { 4th+ } \\
\text { Generation }\end{array}$ \\
\hline \multicolumn{3}{|c|}{ Percent of fathers reporting poor health status: } \\
\hline Mexican on both sides of the family & $\begin{array}{l}8.55 \\
(.49)\end{array}$ & $\begin{array}{l}9.76 \\
(.46)\end{array}$ \\
\hline Mexican on one side of the family & $\begin{array}{l}5.82 \\
(.46)\end{array}$ & $\begin{array}{l}6.08 \\
(.29)\end{array}$ \\
\hline All & $\begin{array}{l}7.35 \\
(.34)\end{array}$ & $\begin{array}{l}7.51 \\
(.25)\end{array}$ \\
\hline \multicolumn{3}{|c|}{ Percent of mothers reporting poor health status: } \\
\hline Mexican on both sides of the family & $\begin{array}{l}6.84 \\
(.44)\end{array}$ & $\begin{array}{l}7.35 \\
(.40)\end{array}$ \\
\hline Mexican on one side of the family & $\begin{array}{l}5.93 \\
(.47)\end{array}$ & $\begin{array}{l}6.72 \\
(.31)\end{array}$ \\
\hline All & $\begin{array}{l}6.44 \\
(.32)\end{array}$ & $\begin{array}{l}6.96 \\
(.24)\end{array}$ \\
\hline
\end{tabular}

Source: 1996-2017 CPS March supplement data.

Note: Standard errors are shown in parentheses. The samples include U.S.-born children ages 17 and below who live in intact families. $3^{\text {rd }}$ generation Mexicans are U.S.-born, have two U.S.-born parents, and at least one grandparent born in Mexico. $4^{\text {th }}+$ generation Mexicans are U.S.-born, have two U.S.born parents, have no grandparents born in Mexico, and at least one parent who identifies as Mexican on the Hispanic origin question. 


\section{Table 5: Poor health status of parents of children ages 17 and younger, by child's}

Mexican identification

\begin{tabular}{|c|c|c|}
\hline & $\begin{array}{c}\text { rd } \\
\text { Generation }\end{array}$ & $\begin{array}{c}\text { 4th+ } \\
\text { Generation }\end{array}$ \\
\hline \multicolumn{3}{|c|}{ Percent of fathers reporting poor health status: } \\
\hline Child identified as Mexican & $\begin{array}{l}7.75 \\
(.39)\end{array}$ & $\begin{array}{l}8.29 \\
(.30)\end{array}$ \\
\hline Child not identified as Mexican & $\begin{array}{l}5.58 \\
(.69)\end{array}$ & $\begin{array}{l}4.89 \\
(.43)\end{array}$ \\
\hline All & $\begin{array}{l}7.35 \\
(.34)\end{array}$ & $\begin{array}{l}7.51 \\
(.25)\end{array}$ \\
\hline \multicolumn{3}{|c|}{ Percent of mothers reporting poor health status: } \\
\hline Child identified as Mexican & $\begin{array}{l}6.39 \\
(.35)\end{array}$ & $\begin{array}{l}7.13 \\
(.28)\end{array}$ \\
\hline Child not identified as Mexican & $\begin{array}{l}6.67 \\
(.75)\end{array}$ & $\begin{array}{l}6.41 \\
(.49)\end{array}$ \\
\hline All & $\begin{array}{c}6.44 \\
(.32)\end{array}$ & $\begin{array}{l}6.96 \\
(.24)\end{array}$ \\
\hline
\end{tabular}

Source: 1996-2017 CPS March supplement data.

Note: Standard errors are shown in parentheses. The samples include U.S.-born children ages 17 and below who live in intact families. $3^{\text {rd }}$ generation Mexicans are U.S.-born, have two U.S.-born parents, and at least one grandparent born in Mexico. $4^{\text {th }}+$ generation Mexicans are U.S.-born, have two U.S.-born parents, have no grandparents born in Mexico, and at least one parent who identifies as Mexican on the Hispanic origin question. 
Table 6: Percentage of children ages 17 and younger reporting poor health status, by Mexican generation

\begin{tabular}{|c|c|c|c|c|c|c|c|c|c|}
\hline & \multicolumn{8}{|c|}{ Mexicans } & \multirow[b]{2}{*}{$\begin{array}{c}4^{\text {th }}+ \\
\text { Generation White }\end{array}$} \\
\hline & \multirow[t]{2}{*}{$\begin{array}{c}1.5 \\
\text { Generation } \\
\end{array}$} & \multirow[t]{2}{*}{$\begin{array}{c}\text { 2nd } \\
\text { Generation }\end{array}$} & \multicolumn{3}{|c|}{$\begin{array}{c}\text { 3rd Generation } \\
\text { Identified as Mexican }\end{array}$} & \multicolumn{3}{|c|}{$\begin{array}{c}\text { 4th+ Generation } \\
\text { Identified as Mexican }\end{array}$} & \\
\hline & & & Yes & $\mathrm{No}$ & All & Yes & No & All & \\
\hline Poor health (\%) & $\begin{array}{l}2.59 \\
(.22)\end{array}$ & $\begin{array}{l}2.52 \\
(.09)\end{array}$ & $\begin{array}{l}1.74 \\
(.19)\end{array}$ & $\begin{array}{l}1.46 \\
(.36)\end{array}$ & $\begin{array}{l}1.69 \\
(.17)\end{array}$ & $\begin{array}{l}1.82 \\
(.15)\end{array}$ & $\begin{array}{l}1.44 \\
(.24)\end{array}$ & $\begin{array}{l}1.74 \\
(.13)\end{array}$ & $\begin{array}{l}1.24 \\
(.02)\end{array}$ \\
\hline Sample size & 5,328 & 29,185 & 4,773 & 1,094 & 5,867 & 8,335 & 2,495 & 10,830 & 211,699 \\
\hline
\end{tabular}

Source: 1996-2017 CPS March supplement data.

Note: Standard errors are shown in parentheses. The samples include U.S.- and Mexican-born children ages 17 and below who live in intact families. 1.5 generation Mexicans are children born in Mexico. $2^{\text {nd }}$ generation Mexicans are U.S.-born and have at least one parent born in Mexico. $3^{\text {rd }}$ generation Mexicans are U.S.-born, have two U.S.-born parents, and at least one grandparent born in Mexico. $4^{\text {th }}+$ generation Mexicans are U.S.-born, have two U.S.-born parents, have no grandparents born in Mexico, and at least one parent who identifies as Mexican on the Hispanic origin question. 4th+ generation whites have no parents or grandparents who are foreign born, and themselves and both parents are identified as non-Hispanic on the Hispanic origin question and white only on the race question. 
Table 7: Child poor health regressions for Mexican generations relative to $4^{\text {th }}+$ generation whites.

\begin{tabular}{|c|c|c|c|c|}
\hline & $(1)$ & $(2)$ & (3) & (4) \\
\hline 1.5 generation Mexican & $\begin{array}{l}.0135^{* * *} \\
(.0017)\end{array}$ & $\begin{array}{l}.0132^{* * *} \\
(.0017)\end{array}$ & $\begin{array}{l}.0019 \\
(.0018)\end{array}$ & $\begin{array}{l}.0043^{*} \\
(.0018)\end{array}$ \\
\hline $2^{\text {nd }}$ generation Mexican & $\begin{array}{l}.0128^{* * *} \\
(.0007)\end{array}$ & $\begin{array}{l}.0135^{* * *} \\
(.0009)\end{array}$ & $\begin{array}{l}.0045^{* * *} \\
(.0010)\end{array}$ & $\begin{array}{l}.0052^{* * *} \\
(.0010)\end{array}$ \\
\hline $\begin{array}{l}3^{\text {rd }} \text { generation Mexican: } \\
\text { Identified as Mexican }\end{array}$ & $\begin{array}{l}.0050^{* *} \\
(.0017)\end{array}$ & $\begin{array}{l}.0052^{* *} \\
(.0018)\end{array}$ & $\begin{array}{l}.0025 \\
(.0018)\end{array}$ & $\begin{array}{l}.0016 \\
(.0018)\end{array}$ \\
\hline Not Identified as Mexican & $\begin{array}{c}.0022 \\
(.0036)\end{array}$ & $\begin{array}{l}.0020 \\
(.0036)\end{array}$ & $\begin{array}{c}.0006 \\
(.0036)\end{array}$ & $\begin{array}{l}-.0003 \\
(.0036)\end{array}$ \\
\hline $\begin{array}{c}4^{\text {th }}+\text { generation Mexican: } \\
\text { Identified as Mexican }\end{array}$ & $\begin{array}{l}.0058^{* * *} \\
(.0013)\end{array}$ & $\begin{array}{l}.0055^{* * *} \\
(.0014)\end{array}$ & $\begin{array}{l}.0026 \\
(.0014)\end{array}$ & $\begin{array}{l}.0014 \\
(.0014)\end{array}$ \\
\hline Not Identified as Mexican & $\begin{array}{l}.0020 \\
(.0024)\end{array}$ & $\begin{array}{c}.0017 \\
(.0024)\end{array}$ & $\begin{array}{c}.0000 \\
(.0024)\end{array}$ & $\begin{array}{l}-.0001 \\
(.0024)\end{array}$ \\
\hline Basic controls & No & Yes & Yes & Yes \\
\hline SES & No & No & Yes & Yes \\
\hline Parental health & No & No & No & Yes \\
\hline Average poor health & .0144 & .0144 & .0144 & .0144 \\
\hline Sample size & 262,909 & 262,909 & 262,909 & 262,909 \\
\hline
\end{tabular}

Source: 1996-2017 CPS March supplement data.

Note: Standard errors are shown in parentheses. The samples include U.S.- and Mexican-born children ages 17 and below who live in intact families. 1.5 generation Mexicans are children born in Mexico. $2^{\text {nd }}$ generation Mexicans are U.S.-born and have at least one parent born in Mexico. $3^{\text {rd }}$ generation Mexicans are U.S.-born, have two U.S.-born parents, and at least one grandparent born in Mexico. $4^{\text {th }}+$ generation Mexicans are U.S.-born, have two U.S.-born parents, have no grandparents born in Mexico, and at least one parent who identifies as Mexican on the Hispanic origin question. 4th+ generation whites have no parents or grandparents who are foreign born, and themselves and both parents are identified as non-Hispanic on the Hispanic origin question and white only on the race question. $4^{\text {th }}+$ generation whites is the reference group. Each column reports estimates from a separate ordinary least squares regression of the form: $H_{i}=\beta I_{i}+X_{i} \pi+\varepsilon_{i}$, where $H_{i}=1$ if child $i$ has poor/fail health, and $I_{i}$ is a vector including the following dummy variables: 1.5 Generation Mexican, $2^{\text {nd }}$ Generation Mexican, $3^{\text {rd }}$ Generation Mexican Identified as Mexican, $3^{\text {rd }}$ Generation Mexican Not Identified as Mexican, $4^{\text {th }}+$ Generation Mexican Identified as Mexican, and $4^{\text {th }}+$ Generation Mexican Not Identified as Mexican. Controls $\left(X_{i}\right)$, where indicated, are as follows. Basic controls include age, age squared, and dummy variables for gender, survey year, division of the country, individual states NY, NJ, IL, FL, TX, NM, AZ, CA, and urban area. SES controls include controls for mother's and father's years of education and employment status. Parental health controls include dummy variables for mother's and father's self-reported health status. 
APPENDIX 
Table A1: The relationship between health conditions and poor/fair health among 0-17 year-old children, by Mexican generation

\begin{tabular}{|c|c|c|c|c|c|c|c|c|c|c|c|c|}
\hline & \multicolumn{3}{|c|}{ 1.5 Generation Mexican } & \multicolumn{3}{|c|}{ 2nd Generation Mexican } & \multicolumn{3}{|c|}{ 3rd+ Generation Mexican } & \multicolumn{3}{|c|}{ 3rd+ Generation Whites } \\
\hline & $\begin{array}{c}\text { Sample } \\
\text { size }\end{array}$ & $\begin{array}{l}\text { Fraction } \\
\text { w/ Cond. }\end{array}$ & $\hat{\beta}$ & $\begin{array}{c}\text { Sample } \\
\text { size }\end{array}$ & $\begin{array}{l}\text { Fraction } \\
\text { w/ Cond. }\end{array}$ & $\hat{\beta}$ & $\begin{array}{c}\text { Sample } \\
\text { size }\end{array}$ & $\begin{array}{l}\text { Fraction } \\
\text { w/ Cond. }\end{array}$ & $\hat{\beta}$ & $\begin{array}{c}\text { Sample } \\
\text { size }\end{array}$ & $\begin{array}{l}\text { Fraction } \\
\text { w/ Cond. }\end{array}$ & $\hat{\beta}$ \\
\hline Chronic condition & 5,946 & .0254 & $\begin{array}{l}.1151^{* * *} \\
(.0281)\end{array}$ & 37,870 & .0392 & $\begin{array}{l}.1392^{* * *} \\
(.0096)\end{array}$ & 13,729 & .0573 & $\begin{array}{l}.0920^{* * *} \\
(.0108)\end{array}$ & 105,627 & .0669 & $\begin{array}{l}.0601^{* * * *} \\
(.0030)\end{array}$ \\
\hline Health limitation & 5,946 & .0262 & $\begin{array}{l}.1107^{* * *} \\
(.0273)\end{array}$ & 37,870 & .0400 & $\begin{array}{l}.1358^{* * *} \\
(.0094)\end{array}$ & 13,729 & .0584 & $\begin{array}{l}.0914^{* * *} \\
(.0107)\end{array}$ & 105,627 & .0679 & $\begin{array}{l}.0594^{* * *} \\
(.0029)\end{array}$ \\
\hline Health condition & 5,946 & .103 & $\begin{array}{l}.0306^{* * *} \\
(.0092)\end{array}$ & 37,870 & .127 & $\begin{array}{l}.0401^{* * *} \\
(.0035)\end{array}$ & 13,729 & .182 & $\begin{array}{l}.0157^{* * *} \\
(.0034)\end{array}$ & 105,627 & .205 & $\begin{array}{l}.0126^{* * *} \\
(.0010)\end{array}$ \\
\hline Allergy ${ }^{1}$ & 2,354 & .129 & $\begin{array}{l}.0332^{* * *} \\
(.0133)\end{array}$ & 15,611 & .162 & $\begin{array}{l}.0463^{* * *} \\
(.0051)\end{array}$ & 6,190 & .256 & $\begin{array}{l}.0135^{* * *} \\
(.0041)\end{array}$ & 51,491 & .276 & $\begin{array}{l}.0136^{* * *} \\
(.0012)\end{array}$ \\
\hline Ear infection ${ }^{1}$ & 2,358 & .0310 & $\begin{array}{c}.0316 \\
(.0271)\end{array}$ & 15,626 & .0604 & $\begin{array}{l}.0609^{* * *} \\
(.0091)\end{array}$ & 6,207 & .0657 & $\begin{array}{l}.0428^{* * * *} \\
(.0109)\end{array}$ & 51,638 & .0656 & $\begin{array}{l}.0211^{\text {**** }} \\
(.0029)\end{array}$ \\
\hline Developmental delay $^{1}$ & 2,357 & .0132 & $\begin{array}{l}.1051^{*} \\
(.0603)\end{array}$ & 15,625 & .0188 & $\begin{array}{l}.1599^{* * *} \\
(.0225)\end{array}$ & 6,207 & .0350 & $\begin{array}{l}.0799^{* * *} \\
(.0195)\end{array}$ & 51,627 & .0372 & $\begin{array}{l}.0738^{* * *} \\
(.0062)\end{array}$ \\
\hline Chicken pox ${ }^{1}$ & 2,331 & .417 & $\begin{array}{l}.0073 \\
(.0072)\end{array}$ & 15,558 & .207 & $\begin{array}{l}-.0019 \\
(.0042)\end{array}$ & 6,172 & .228 & $\begin{array}{c}.0032 \\
(.0047)\end{array}$ & 51,338 & .289 & $\begin{array}{l}.0014 \\
(.0013)\end{array}$ \\
\hline Low birth weight ${ }^{1}$ & 1,932 & .138 & $\begin{array}{l}.0078 \\
(.0113)\end{array}$ & 14,353 & .0798 & $\begin{array}{l}.0208^{* * *} \\
(.0064)\end{array}$ & 5,902 & .0749 & $\begin{array}{l}.0046 \\
(.0065)\end{array}$ & 49,885 & .0700 & $\begin{array}{l}.0115^{* * *} \\
(.0024)\end{array}$ \\
\hline $\mathrm{ADHD}^{1}$ & 2,323 & .0125 & $\begin{array}{l}-.0237^{\text {**** }} \\
(.0074)\end{array}$ & 13,192 & .0202 & $\begin{array}{l}.1109^{* * *} \\
(.0215)\end{array}$ & 5,017 & .0439 & $\begin{array}{c}.0211 \\
(.0134)\end{array}$ & 44,073 & .0660 & $\begin{array}{l}.0215^{\text {**** }} \\
(.0032)\end{array}$ \\
\hline Learning disorder ${ }^{1}$ & 2,281 & .0285 & $\begin{array}{l}.0808^{* *} \\
(.0385)\end{array}$ & 12,034 & .0446 & $\begin{array}{l}.0959^{* * *} \\
(.0143)\end{array}$ & 4,494 & .0679 & $\begin{array}{l}.0530^{* * *} \\
(.0142)\end{array}$ & 40,685 & .0665 & $\begin{array}{l}.0435^{\text {**** }} \\
(.0043)\end{array}$ \\
\hline Missed school days ${ }^{1,2}$ & 485 & 2.106 & $\begin{array}{l}.0037^{* *} \\
(.0016)\end{array}$ & 9,761 & 2.531 & $\begin{array}{l}.0066^{* * *} \\
(.0010)\end{array}$ & 3,603 & 3.447 & $\begin{array}{l}.0027^{* * *} \\
(.0010)\end{array}$ & 34,246 & 3.538 & $\begin{array}{l}.0036^{* * *} \\
(.0003)\end{array}$ \\
\hline Obese $^{1,2}$ & 485 & .167 & $\begin{array}{l}.0326 \\
(.0245)\end{array}$ & 2,157 & .226 & $\begin{array}{l}.0105 \\
(.0104)\end{array}$ & 695 & .153 & $\begin{array}{c}.0231 \\
(.0199)\end{array}$ & 7,653 & .106 & $\begin{array}{l}.0204^{* * *} \\
(.0064)\end{array}$ \\
\hline
\end{tabular}

Source: 2000-2015 National Health Interview Survey (NHIS). The sample includes U.S.- and Mexican-born children ages 0-17 living with both biological parents.

Sample further limited to: ${ }^{1}$ sample children, ${ }^{2}$ ages 12-17 in the sample years 2008-2014. 1.5 generation Mexican children are foreign-born children with at least one foreign-born parent. 2 nd generation Mexican children are U.S.-born children with at least one foreign born parent. 3rd+ generation Mexican children are U.S.-born with two U.S.-born parents. Each $\hat{\beta}$ is from a separate ordinary least squares regression of the form: $H_{i}=\beta C_{i}+X_{i} \pi+\varepsilon_{i}$, where $H_{i}=1$ if child $i$ has poor/fail health, and $C_{i}=1$ if child $i$ has the indicated health condition. Controls $\left(X_{i}\right)$ include child's gender, child's integer age fixed effects, mother's and father's age (quadratic), mother and father's education fixed effects, 13 family income fixed effects, an indicator variable equal to one if the interview was conducted in Spanish, region fixed effects, and year fixed effects. 